\title{
Recent Changes in the Moisture Source of Precipitation over the Tibetan Plateau 0
}

\author{
CHI ZHANG AND QIUHONG TANG \\ Key Laboratory of Water Cycle and Related Land Surface Processes, Institute of Geographic Sciences and \\ Natural Resources Research, Chinese Academy of Sciences, Beijing, China \\ DELIANG CHEN \\ Regional Climate Group, Department of Earth Sciences, University of Gothenburg, Gothenburg, Sweden
}

(Manuscript received 26 November 2015, in final form 30 October 2016)

\begin{abstract}
Evidence has suggested a wetting trend over part of the Tibetan Plateau (TP) in recent decades, although there are large uncertainties in this trend due to sparse observations. Examining the change in the moisture source for precipitation over a region in the TP with the most obvious increasing precipitation trend may help understand the precipitation change. This study applied the modified Water Accounting Model with two atmospheric reanalyses, ground-observed precipitation, and evaporation from a land surface model to investigate the change in moisture source of the precipitation over the targeted region. The study estimated that on average more than $69 \%$ and more than $21 \%$ of the moisture supply to precipitation over the targeted region came from land and ocean, respectively. The moisture transports from the west of the TP by the westerlies and from the southwest by the Indian summer monsoon likely contributed the most to precipitation over the targeted region. The moisture from inside the region may have contributed about $18 \%$ of the total precipitation. Most of the increased moisture supply to the precipitation during 1979-2013 was attributed to the enhanced influx from the southwest and the local moisture supply. The precipitation recycling ratio over the targeted region increased significantly, suggesting an intensified hydrological cycle. Further analysis at monthly scale and with wet-dryyear composites indicates that the increased moisture contribution was mainly from the southwest and the targeted region during May and September. The enhanced water vapor transport from the Indian Ocean during July and September and the intensified local hydrological recycling seem to be the primary reasons behind the recent precipitation increase over the targeted region.
\end{abstract}

\section{Introduction}

The Tibetan Plateau (TP), also known as the "third pole," exerts an important influence on regional and hemispheric climate. Environmental change on the TP has drawn the attention of many scientists (e.g., Liu et al. 2007; Nan et al. 2009; Sun and Ding 2011; Yao et al. 2012; Lan et al. 2013; Gao et al. 2014; Klein et al. 2014). All the existing studies (Krause et al. 2010; Yang et al. 2011; Moore 2012; Gao et al. 2015; Chen et al. 2015) show that

Supplemental information related to this paper is available at the Journals Online website: http://dx.doi.org/10.1175/ JCLI-D-15-0842.s1.

Corresponding author e-mail: Qiuhong Tang, tangqh@igsnrr. ac.cn over the past several decades, the TP has experienced a rapid warming and an overall wetting. Although precipitation change over the TP shows large spatial and temporal variability, an overall increasing trend in precipitation is supported by ground observations from various sources (You et al. 2008; Wu and Zhu 2008; Zhu et al. 2010; Yao et al. 2012).

Large-scale atmospheric circulations, such as the North Atlantic Oscillation, the Arctic Oscillation, and the East Asian westerly jet, may have influenced precipitation over the TP (e.g., Lan et al. 2013; Liu et al. 2016). Changes in local circulation may also have played a role in the spatial distribution of TP's wetting (Gao et al. 2014).

Generally, precipitation consists of three indispensable conditions: moisture sources (regions of evaporation), transport paths, and uplifting motions (Gustafsson 
et al. 2010). Among them, the most puzzling is the origin of water vapor that produces the precipitation (Stohl and James 2004). Increased precipitation over the TP indicates that more water vapor, from either the internal sources over the TP or external moisture sources (Gao et al. 2014), may be available to produce the increased precipitation. If the local water vapor supply plays a major role in the precipitation change, then an intensified precipitation recycling in a warmer climate may have been responsible for the precipitation increase (Guo and Wang 2014). Otherwise, the precipitation change in the TP may be mainly due to changes in external moisture transport (Curio et al. 2015). A change in the contributions of moisture sources to the TP precipitation would mainly reflect a change in the largescale circulation systems over the TP. Certainly, the moisture source of TP precipitation and its change merit further investigation.

There have been many studies on the moisture transport and moisture origins of TP precipitation. Sugimoto et al. (2008) found that the summer water vapor advection to the TP was influenced by two types of synopticscale systems, that is, the stationary Tibetan high and migrating troughs. While the prevailing Tibetan high prevents water vapor intrusion from the south to the TP, synoptic troughs help transport water vapor to the TP from the south via monsoon and westerlies flows. Feng and Zhou (2012) pointed out that climatologically there were two main channels for moisture supply to summer precipitation over the TP. The first was characterized by transport of the Indian summer monsoon through deep canyons in the southeastern part of the TP, and the second was transported through the southern branch of the westerlies. Moisture transported from the north was found to be relatively little. Chen et al. (2012) identified the moisture sources of TP precipitation using Global Forecast System (GFS) data from NCEP. They found a main moisture source located from the Indian subcontinent to the Southern Hemisphere and two additional sources located in the Bay of Bengal and the northwestern part of the TP. In a recent study by Sun and Wang (2014), the moisture contributions from different source areas to the eastern TP precipitation were quantified using a more sophisticated method. The results indicate that most moisture released over the eastern TP was from the Eurasian continent throughout the year. Although the moisture uptake over oceanic sources was considerable, much was lost en route.

Although the moisture source regions for TP precipitation are starting to be identified, the change in the moisture sources over time has not yet been studied in any detail. More specifically, the moisture source of the increased TP precipitation needs further investigation in order to understand the recent wetting of the TP. Guo and Wang (2014) studied the change in precipitation recycling in different parts of the TP, but they did not identify the contribution from external moisture sources. To understand the recent wetting trend over the TP, this study focuses on identifying changes in moisture sources for the TP precipitation from 1979 to 2013.

\section{Data and methodology}

\section{a. Data}

This study applies the Water Accounting Model (WAM; van der Ent et al. 2010; van der Ent and Savenije 2011) to track the precipitation moisture of the TP. The model input data include atmospheric moisture content and wind, surface pressure, precipitation, and evaporation.

Two atmospheric reanalyses-that is, the European Centre for Medium-Range Weather Forecasts (ECMWF) interim reanalysis (ERA-Interim, hereafter ERA-I; $1.5^{\circ} \times 1.5^{\circ}$ grid) (Dee et al. 2011) and the National Centers for Environmental Prediction (NCEP)-U.S. Department of Energy (DOE) AMIP-II reanalysis (NCEP-2; $2.5^{\circ} \times 2.5^{\circ}$ grid) (Kanamitsu et al. 2002) were used for wind, humidity, and surface pressure. ERA-I is used as the primary data, while NCEP-2 is supplementary, since ERA-I performs better than other reanalyses in atmospheric water budget over the TP (Gao et al. 2014). The ERA-I data include 6-hourly specific humidity, zonal, and meridional wind speeds at the lowest 23 pressure levels $(200-1000 \mathrm{hPa})$, and surface pressure from 1979 to 2013. The NCEP-2 data include 6-hourly relative humidity, zonal, and meridional wind speeds at the lowest 10 pressure levels $(200-1000 \mathrm{hPa})$, and surface pressure of the same period.

The atmospheric data are used to calculate the precipitable water and water vapor flux according to

$$
\begin{aligned}
& W=-\frac{1}{g} \int_{p_{\text {surf }}}^{200 \mathrm{hPa}} q d p \quad \text { and } \\
& Q=-\frac{1}{g} \int_{p_{\text {surf }}}^{200 \mathrm{hPa}} V q d p
\end{aligned}
$$

where $W$ is the precipitable water in the troposphere, $g$ is the acceleration of gravity, $q$ is the specific humidity, $P_{\text {surf }}$ is the surface pressure, $Q$ is the vertically integrated water vapor flux, and $V$ is the horizontal wind vector.

The ground-based gridded daily precipitation on a $0.5^{\circ} \times 0.5^{\circ}$ grid were obtained from the National Meteorological Information Center (NMIC), China Meteorological Administration (CMA). This dataset was derived from quality-controlled (but not homogenized) station records of daily precipitation from 2472 stations 
over China since 1961. The gridding used the thin-plate smooth spline method with the elevation effects being taken care of (Zhao et al. 2014; Zhao and Zhu 2015). The 3-hourly ERA-I precipitation is too inaccurate to be used directly, yet it contains the information of diurnal variation. To keep this information, the CMA dataset was utilized to rescale the ERA-I precipitation. The CMA precipitation from 1979 to 2013 was first transformed to the same spatial resolution as ERA-I by taking the means of the $0.5^{\circ}$ grids that fall into the $1.5^{\circ}$ grid. Then both monthly CMA and ERA-I precipitation were calculated. By setting the monthly CMA precipitation as the norm, all ERA-I precipitation during a month was rescaled proportionally.

The land evaporation in atmospheric reanalyses is also too inaccurate. Because of the scarcity and quality issues of the observed evapotranspiration, simulated data from land surface models are often applied for evapotranspiration analysis (Yang et al. 2011; Yin et al. 2012). According to Gao et al. (2014), the Global Land Data Assimilation System (GLDAS) data can be considered reliable, since the model forcing data, including precipitation, temperature, and radiation, are observed and the models are physically based and are subject to vigorous evaluation. The 3 -hourly $1^{\circ}$-gridded GLDAS evaporation from the Community Land Model was interpolated into $1.5^{\circ}$-gridded data. Evaporation over the sea surface in ERA-I was kept. For NCEP-2, both the $1.5^{\circ}$-gridded evaporation and precipitation were downscaled to produce $2.5^{\circ}$-gridded data through bilinear interpolation.

The trend of annual precipitation calculated from the CMA dataset over west China containing the TP from 1979 to 2013 is shown in Fig. 1a. The TP exhibits an overall wetting trend in particular in the west-central TP. We selected a continuous area with the largest positive trend in precipitation for further analysis (red box in Fig. 1a as the targeted region, also the westcentral TP). There are some gauge stations around this region. All these stations exhibit an increasing trend of precipitation. However, these stations are not distributed evenly, with most stations located in the east and south. More importantly, the number of the stations inside this region is small. The time series of the annual precipitation for the targeted area are shown in Fig. 1b, which shows a significant increasing trend. It should be noted that the magnitude of the trend may have large uncertainty due to the sparsely distributed observation stations over the targeted region, which is further discussed in the discussion section. The dry years that are one standard deviation or more below the average precipitation happen to be in the first half period, while the wet years selected in the similar way are all in the second half. This is consistent with the wetting trend in the west-central TP. The wet years contain year 1996. Since precipitation and runoff in 1996 for all the GLDAS four land models were found significantly anomalous (Zhou et al. 2013), the GLDAS evaporation data in 1996 were thus considered unreliable. Therefore, in the composite analysis referring to the wet years in this study, the result from 1996 was excluded.

\section{b. Model and methodology}

WAM is a moisture recycling model that can quantify the source-sink relations between evaporation and precipitation (van der Ent et al. 2010; van der Ent and Savenije 2011). The basic equation of WAM is the equation of atmospheric moisture balance, defined as

$$
\frac{\partial W}{\partial t}+\frac{\partial(W u)}{\partial x}+\frac{\partial(W v)}{\partial y}=E-P+\alpha,
$$

where $W$ stands for the precipitable water contained in the air column; $u$ and $v$ stand for the moisture massweighted zonal $x$ and meridional $y$ wind velocities, respectively; $E$ is evaporation; $P$ is precipitation; and $\alpha$ is a residual term that is necessary, since the water budget is usually not closed when using assimilated data. The moisture from a certain source region also follows a similar relationship,

$$
\frac{\partial W_{\Omega}}{\partial t}+\frac{\partial\left(W_{\Omega} u\right)}{\partial x}+\frac{\partial\left(W_{\Omega} v\right)}{\partial y}=E_{\Omega}-P_{\Omega}+\alpha_{\Omega},
$$

where $\Omega$ stands for the source region from where the moisture is evaporated.

WAM is able to track the moisture both forward and backward in time (van der Ent et al. 2013). The algorithms are similar. In the case of forward tracking, the moisture sources [denoted as $\Omega$ in Eq. (4)] evaporates E0 into the atmosphere, which is taken as tagged water in the model. In each grid column, the tagged water is well mixed with the precipitable water with a mix ratio $r$. If it precipitates $\mathrm{P} 0$ in the grid, then the tagged water contributes $\mathrm{P} 0 \times r$, which is the contribution of the moisture sources, leaving $(\mathrm{E} 0-\mathrm{P} 0) \times r$ tagged water in the air. Moisture continues to be evaporated from moisture sources, adding to the tagged water. As the water vapor flows away, the tagged water also flows with it, contributing to precipitation downstream. When backtracking the moisture, the flow occurs in a reverse way, taking precipitation as the source term and evaporation as the sink term (van der Ent et al. 2013).

In this study, one modification with regard to how to deal with the residual term was made. Usually, $\alpha$ is considered to have the same ratio of moisture from the target area to total moisture: $\alpha_{\Omega} / \alpha=W_{\Omega} / W$ (van der Ent 
(a) Precipitation trend $\left(\mathrm{mm} \mathrm{yr}^{-1}\right)$

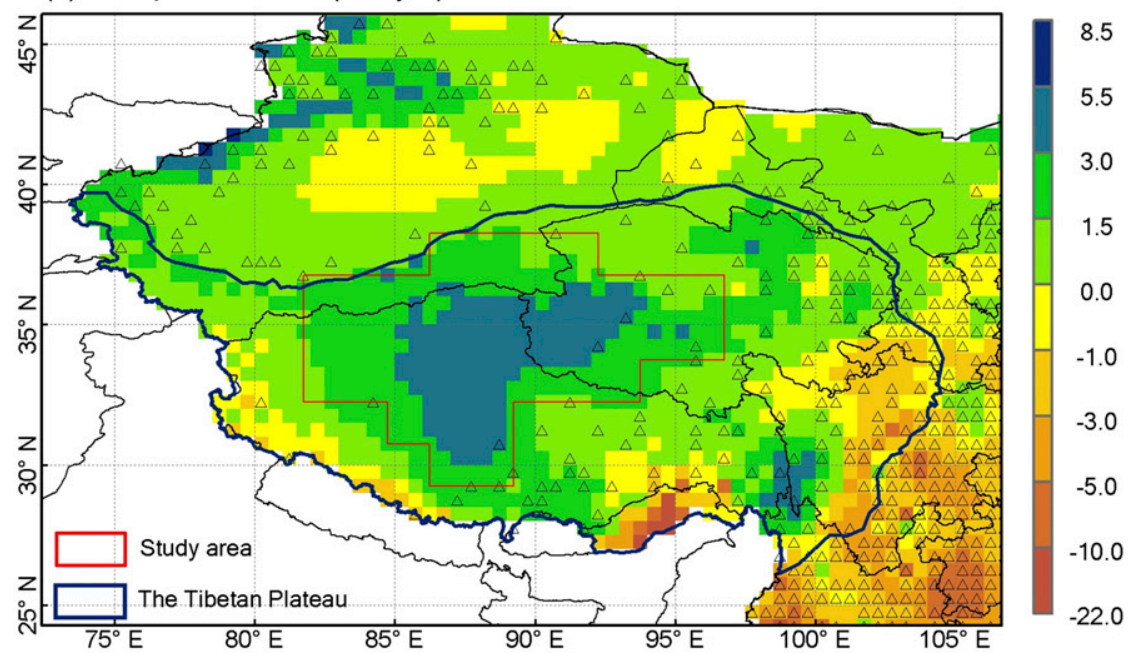

(b) Precipitation series over the TP

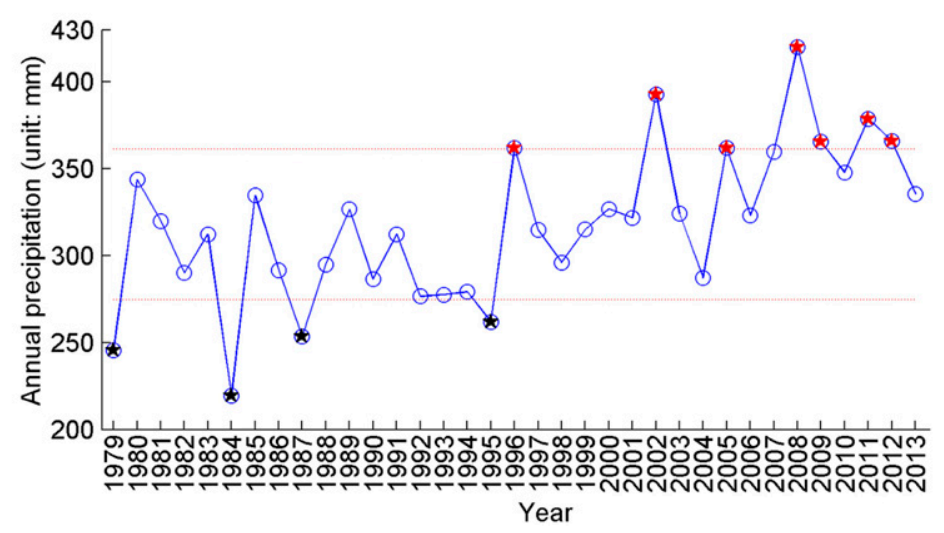

FIG. 1. (a) The trend of annual precipitation calculated from the CMA dataset in west China from 1979 to 2013 . The triangles indicate the $0.5^{\circ}$ grids with continuous station records covering over $90 \%$ of the study period. The blue outlined area delineates the entire TP. The red outlined area delineates the targeted area (i.e., the TP area defined in this study). (b) The time series of the annual precipitation over the targeted region from 1979 to 2013. The dotted red lines bracket the interval with one standard deviation. The dry and wet years with precipitation below or above the dotted red lines are marked with black and red stars, respectively.

et al. 2010). In that way, the tagged water from precipitation will be adjusted along the tracking path and the overall contribution from the moisture sources is not necessarily equal to the precipitation amount. To keep the mass balance of the tracking moisture, the adjustment of tagged water is removed from the computation. By modifying this, WAM ensures the balance of tagged water, which is not true in Lagrangian models.

The average residence time of water vapor in the air is 10 days (Numaguti 1999). For a rain event, the backtracking time is usually set to 10 days before the beginning of precipitation (e.g., Chen et al. 2012; Huang and Cui 2015). In this study, two temporal scales-that is, annual and monthly scales-are used to investigate moisture sources of the TP precipitation. When using the annual scale after one year's tracking, the tagged moisture remaining in the air is negligible compared to the annual precipitation; therefore, it was not considered. When using the monthly scale after one month's tracking, there is still a big amount of tagged water in the air; thus, extra tracking time is set to 30 days to ensure that $95 \%$ of the precipitation moisture returns to the surface.

To maintain numerical stability, the time step in WAM is preliminarily set at $0.5 \mathrm{~h}$ for $1.5^{\circ}$ spacing (van der Ent et al. 2010; van der Ent and Savenije 2011). The 6-hourly precipitable water and integrated moisture flux 
and the 3-hourly evaporation and precipitation were also downscaled to the same time using linear interpolation or equal division (as in van der Ent et al. 2010; van der Ent and Savenije 2011). Although the time step is proper for low-middle-latitude grids, numerical instability still occurs at high latitudes, resulting in abnormal tagged water amount values. As time goes on, this abnormality might propagate to middle or even low-latitude grids. Theoretically, the instability can be limited by reducing the time step. However, in some cases even when the time step was set to $5 \mathrm{~min}$, instability still occurs while the computational time increases exponentially. Therefore, special treatments need to be given in moisture recycling computation at high latitudes. According to previous studies (e.g., Chen et al. 2012; Feng and Zhou 2012), precipitation over the TP comes mostly from the west and south. Since the sources in the far north contribute little to the TP precipitation (Feng and Zhou 2012), the contribution from the northern polar region (to the north of $70^{\circ} \mathrm{N}$ ) was not considered. The contribution of the region to the south of $50^{\circ} \mathrm{S}$ was also excluded for the same reason. In practice, the tagged water in those regions was assigned 0 .

\section{Results}

\section{a. Annual trend of moisture contribution}

The climatology of the moisture contribution to the precipitation over the targeted region on an annual basis from 1979 to 2013 using ERA-I data is shown in Fig. 2a (the blue line encloses high-value grids that totally contribute $90 \%$ of the precipitation over the targeted region, which is also referred to as the main contribution region). Similar results are obtained using NCEP-2 data (Fig. S1 in the supplemental material). The moisture contributions from different grids were not evenly distributed. The major source areas were located in the south and west of TP. Little contribution came from the east. Generally, the moisture contribution of a source to the precipitation sink of the targeted region decreases as its distance to the region increases. Although the Arabian Sea contributed little moisture to the precipitation over the targeted region due to its extremely arid climate, the adjacent seas supplied more water vapor. According to the statistics, within the main contribution region, the land contributed around $69 \%$ of the moisture for the precipitation and the ocean about $21 \%$. For NCEP-2, the main region contributed $85 \%$ of the precipitation over the targeted region, in which $64 \%$ came from the land, and $21 \%$ from the oceans. The moisture of the precipitation over the (a) Climatology of moisture contribution $\left(\mathrm{mm} \mathrm{yr}^{-1}\right)$

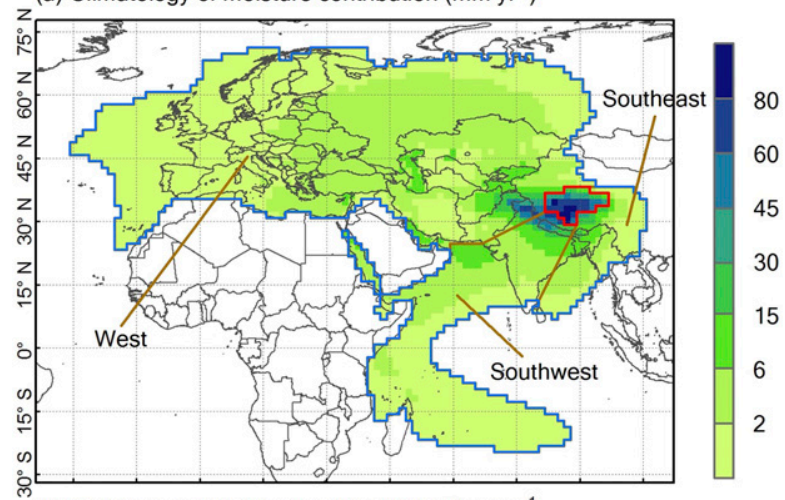

(b) Moisture contribution trend for ERA-I ( $\left.\mathrm{mm} \mathrm{yr}^{-1}\right)$

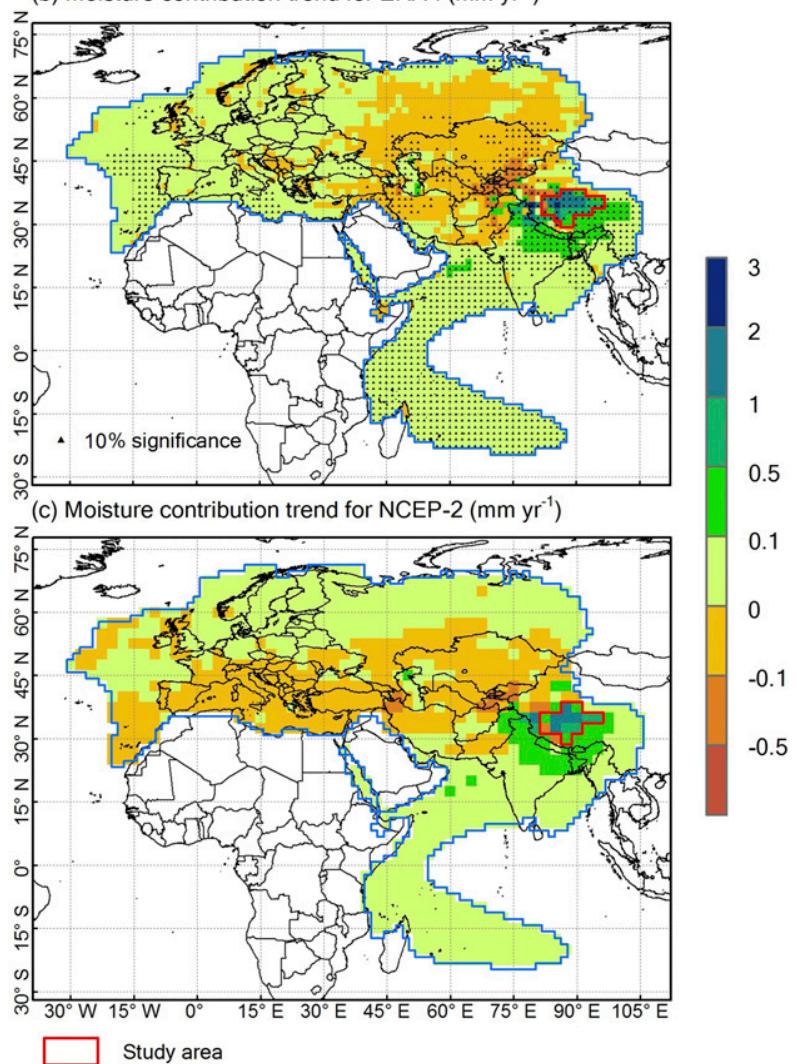

FIG. 2. (a) Climatology of the annual moisture contribution to the precipitation over the targeted region from 1979 to 2013 using ERA-I. The blue line [reproduced in (b) and (c) and Figs. 3 and S1] encloses grids with higher values that cumulatively contribute $90 \%$ of the moisture-causing precipitation in the targeted region. Values outside the blue perimeter are not displayed in the figures hereafter. The orange lines further divide the enclosed area (excluding the targeted region) into the west, southwest, and southeast subregions. (b) The trend of the annual moisture contribution from 1979 to 2013 using ERA-I. The triangles indicate that a trend is detected at the $10 \%$ significance level based on the Student's $t$ test. (c) The trend of the annual moisture contribution from 1979 to 2013 using NCEP-2. 

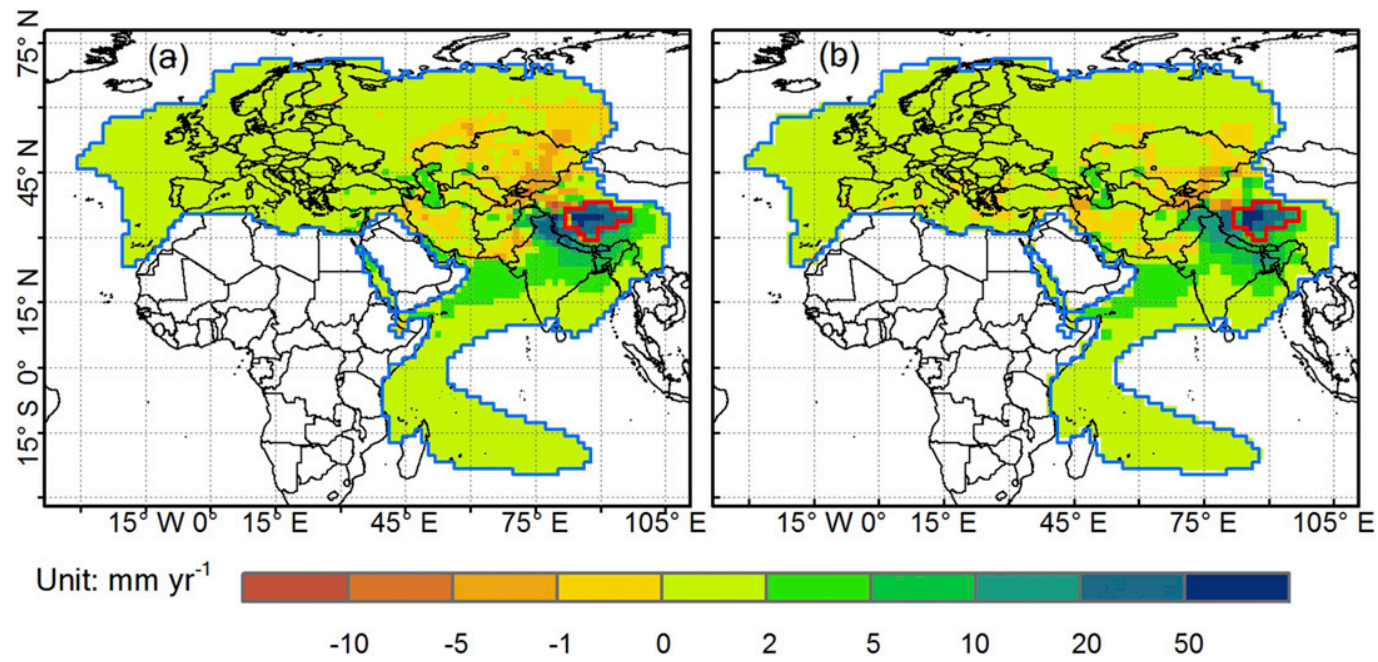

FIG. 3. Annual difference of moisture contribution between wet and dry years (wet mean minus dry mean) from (a) ERA-I and (b) NCEP-2.

targeted region mainly originated from the land on the Eurasian continent.

To further quantify the contribution from different subregions, the main contribution region is divided into four subregions as the orange lines depict in Fig. 2a: the western region is dominated by the westerlies and covers all of Europe and part of the North Atlantic; the southwestern region represents the source area controlled by the Indian summer monsoon; the southeastern region is influenced by the East Asian summer monsoon; and the central region is the west-central TP itself. These four subregions supplied $40 \%, 23 \%, 8 \%$, and $18 \%$ of the moisture for the precipitation over the targeted region, respectively, according to ERA-I. Based on NCEP-2, the contributions from the four subregions are $40 \%, 21 \%, 7 \%$, and $18 \%$, respectively. The East Asian monsoon seems to contribute the least to the precipitation over the targeted region. The estimated local contribution ratios [equivalent to the precipitation recycling ratio (PRR); Brubaker et al. 1993] using the two reanalysis datasets show a close agreement.

The trend of moisture contribution to the precipitation over the targeted region is shown in Figs. $2 \mathrm{~b}$ and $2 \mathrm{c}$ using ERA-I and NCEP-2, respectively. The triangles in Fig. $2 b$ denote areas with a trend at the $10 \%$ significance level. The region that exhibits a significant increasing trend is located in the southeastern part of the main contribution region, where contributions from the targeted west-central TP and the neighboring south increased the most in intensity. Another outstanding feature is that the moisture contribution from central Asia decreased. The spatial pattern of the trends from NCEP-2 is similar to that from
ERA-I. The main difference is that the areas with negative trends in the NCEP-2-based tracking were larger than that using ERA-I. Of all the increased moisture contributions from all grids, the west, southwest, southeast (see Fig. 2), and the targeted region contributed $5 \%, 33 \%, 16 \%$, and $35 \%$, respectively for ERA-I; and 5\%, 37\%, $16 \%$, and $32 \%$, respectively, according to NCEP-2. The distributions among the four subregions estimated by the two reanalyses were pretty close to each other, adding more confidence in our conclusion that the southwest and the targeted region provided most of the additional moisture for increased precipitation over the targeted region. The estimated PRR increased at a rate of $1.4 \%$ decade $^{-1}$, which is statistically significant at the $5 \%$ significance level using ERA-I. This can be compared with a rate of $1.1 \%$ decade $^{-1}$ using NCEP-2, which is significant at the $10 \%$ significance level.

The difference in moisture contribution between the wet and dry years (Fig. 1b) is shown in Fig. 3 (wet mean minus dry mean). Results based on the two reanalyses are generally consistent. Roughly speaking, extra moisture in the wet years in comparison to the dry years was mainly from the targeted region and the south. But there are still some grids in the north and west of the TP that contributed more moisture in the dry years than in the wet years. The respective spatial patterns using different reanalyses resemble those of the trend of the moisture contribution (cf. Figs. 3a and 2b, and Figs. 3b and 2c).

\section{b. Monthly variation of moisture contribution}

Monthly precipitation amounts over the targeted region in the wet and dry years are compared in Fig. 4. During the wet season (i.e., May-September), the difference in 


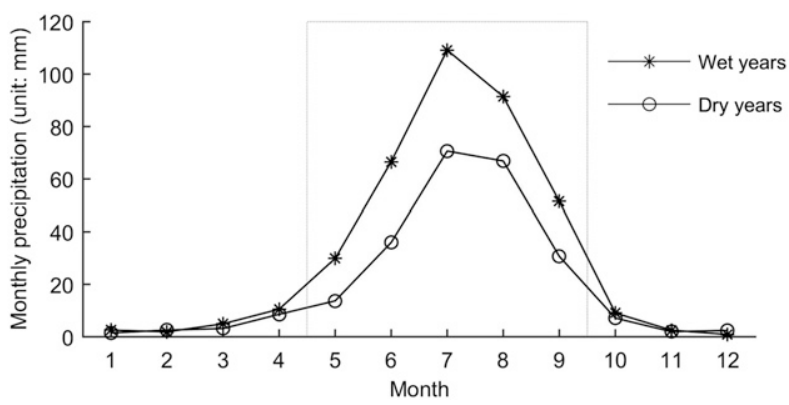

FIG. 4. The composite average monthly precipitation in both wet and dry years. Within the dotted box are the months with significant difference in monthly precipitation between the wet and dry years.

monthly precipitation between the two cases became significant and the maximum appeared in July (Fig. 4). To better understand the big differences in the annual precipitation between the wet and dry years, the moisture source at monthly scale needs to be explored. We focus on the 5 months that differ the most and backtrack each individual month to investigate the monthly changes of moisture sources and to compare the difference between the dry and wet years at the monthly scale.

The mean moisture contribution from May to September during 1979-2013 using ERA-I data is shown in Fig. 5 (the results with NCEP-2 are similar as in Fig. S2 in the supplemental material). In May (Fig. 5a), the majority of the moisture came from the west. The continuous colored region reaches to the central part of the Mediterranean Sea and there was also some contribution from the Arabian Sea. In June, the greater Eurasia continent became the major moisture source. The Somali jet and the South Asian summer monsoon started to bring moisture from the Indian Ocean and the Indian subcontinent to the west-central TP (Fig. 5b). In July, with the highest precipitation throughout the year, the main source region extended to the north, the east, and the south. Moisture contribution from Europe also increased (Fig. 5c). In August, the contribution pattern of moisture sources was similar to July (Fig. 5d). In September, moisture transport to the TP was weakened and the main source region shrank (Fig. 5e). The changes in the monthly moisture sources represent the variations in major circulations, such as the summer monsoon and seasonal changes in evaporation.

The monthly difference of moisture contribution between the wet and dry years (wet minus dry) from ERA-I data is shown in Fig. 6. The vector represents the difference in the monthly water vapor flux (wet minus dry), which helps identify the regions that contributed most to the increased moisture transport. Generally, the more moisture that is transported toward the targeted region from one source, the more moisture the source contributes to the precipitation over the targeted region, and vice versa.

In May and June, the difference in the moisture contribution shows that the extra moisture in the wet years came mainly from the west (Figs. 6a and 6b). Indeed, the western region provided $33 \%$ and $42 \%$ of the extra moisture in these two months (Table 1), respectively. The targeted region itself also contributed a big portion of the extra moisture in the wet years. At the same time, the contributions from the southwest and southeast were minimal. In July, the southwestern region played a major role in providing the extra moisture. The positive difference in the moisture flux from the south (i.e., the southwest and the southeast) means more moisture was transported to the TP. In the same month, the influence of the west in terms of additional moisture supply to the targeted region dropped (Fig. 6c; Table 1), although this subregion provided significant climatological moisture (Fig. 5c). The sources in the neighboring northwest of the west-central TP supplied less moisture, where there was also a decreasing trend in the moisture transport toward the TP.

In August, the difference between the wet and dry years is similar to July. Extra moisture coming from the west accounted for less (Table 1). In September, extra moisture from the west was further weakened and became almost negligible. Instead, the influence of the southwest and southeast was strengthened. In short, the most influential regions contributing to the extra moisture between the wet and dry years in September included most of Indo-China and the entire Indian subcontinent (Fig. 6e). For all the increased moisture in the wet years in comparison to the dry years from May to September, the southwest contributed the most (with a contribution of $30 \%$ ), followed by the targeted region $(26 \%)$, the west $(21 \%)$, and the southeast $(13 \%)$. The monthly differences of the moisture contribution estimated from NCEP-2 (Fig. S3 in the supplemental material shows little difference from those using ERA-I.)

\section{Discussion}

In this study, the precipitation data input for WAM were derived from the CMA ground-based precipitation dataset. It needs to be kept in mind that ground stations over the targeted region are sparse, indicating that the estimated increasing trend of the annual precipitation may contain some uncertainties. To analyze the uncertainties, three additional precipitation products of the same period were used to compare the precipitation 
(a) May

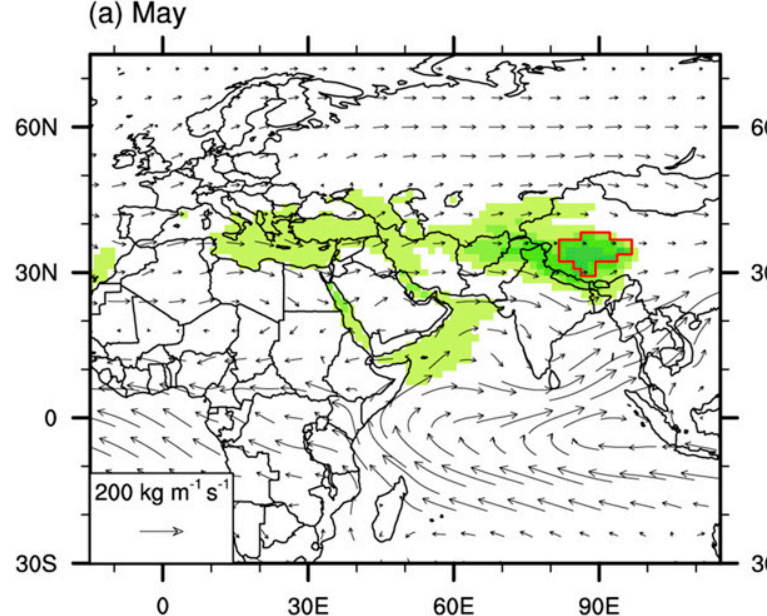

(c) July (b) June

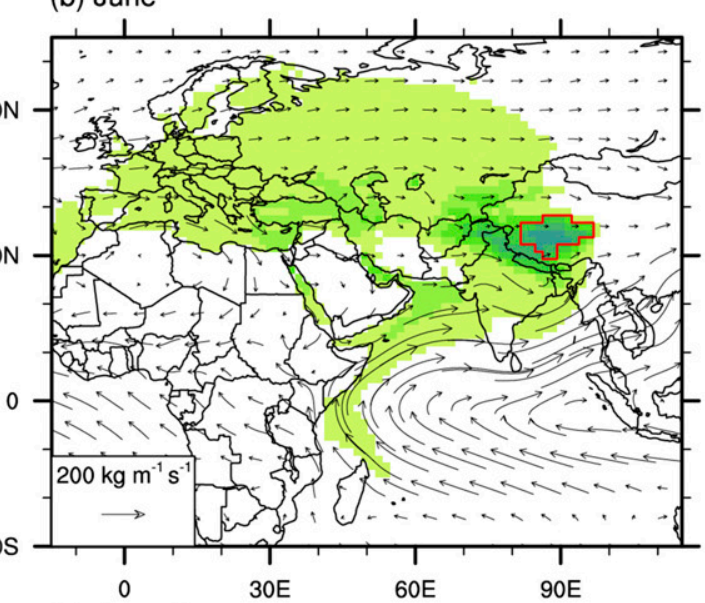

(d) August
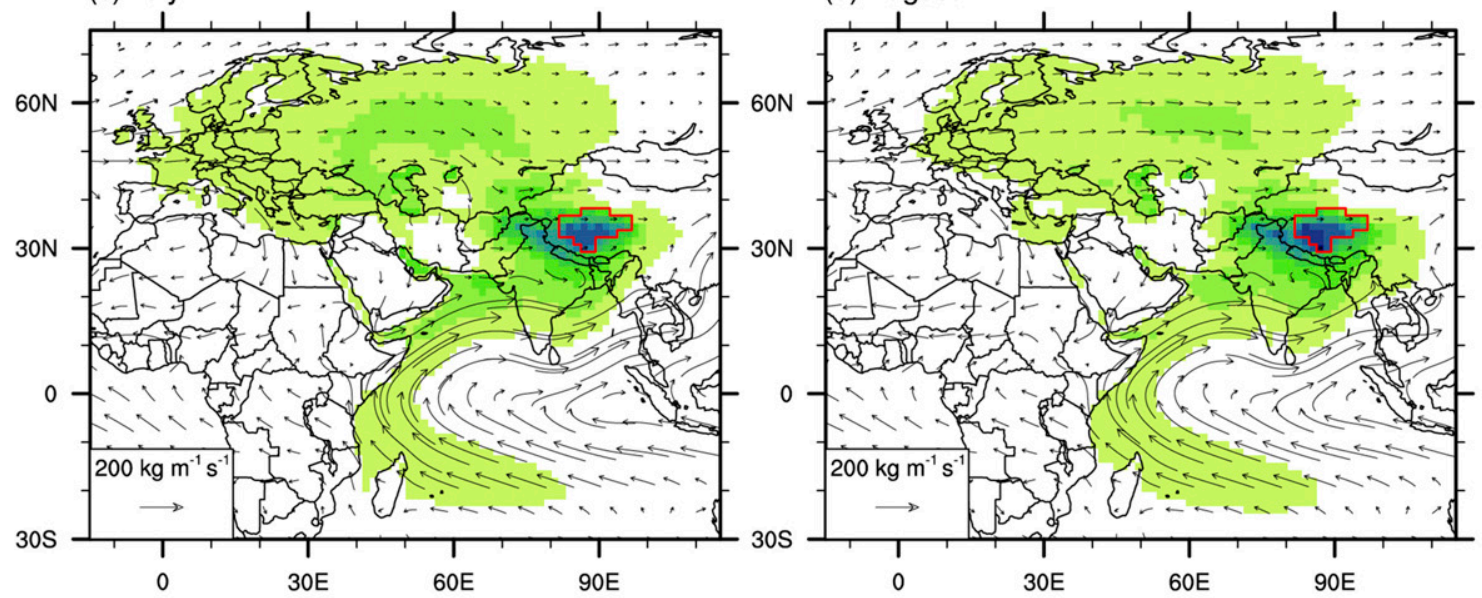

(e) September

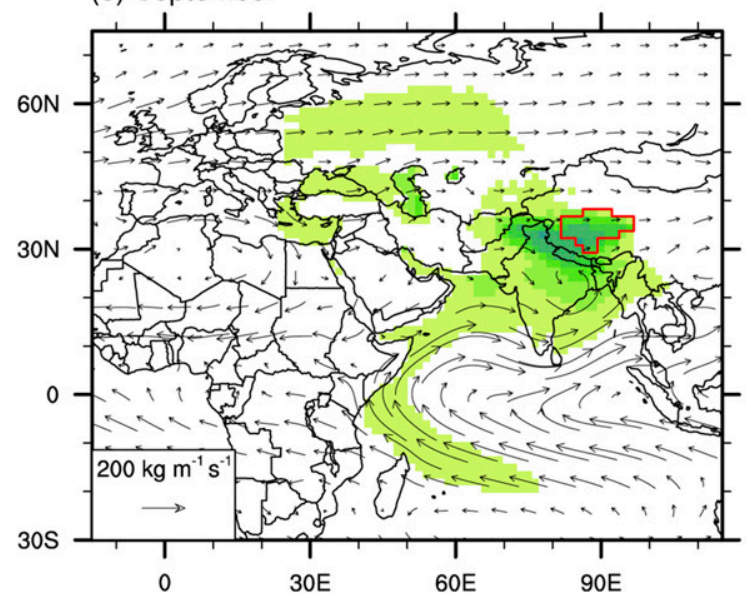

FIG. 5. The climatological moisture contribution $\left(\mathrm{mm} \mathrm{month}^{-1}\right)$ from May to September from 1979 to 2013 using ERA-I. The vectors represent the climatological monthly water vapor flux.

trends over the targeted area. They include two monthly precipitation datasets of the Global Precipitation Climatology Project (GPCP; Adler et al. 2003; Huffman et al. 2009) and the Climate Prediction Center (CPC)
Merged Analysis of Precipitation (CMAP; Xie and Arkin 1997), and the subdaily precipitation dataset from ERA-I. The GPCP and CMAP datasets are $2.5^{\circ}$ gridded and constructed from an analysis of gauge data and 
(a) May

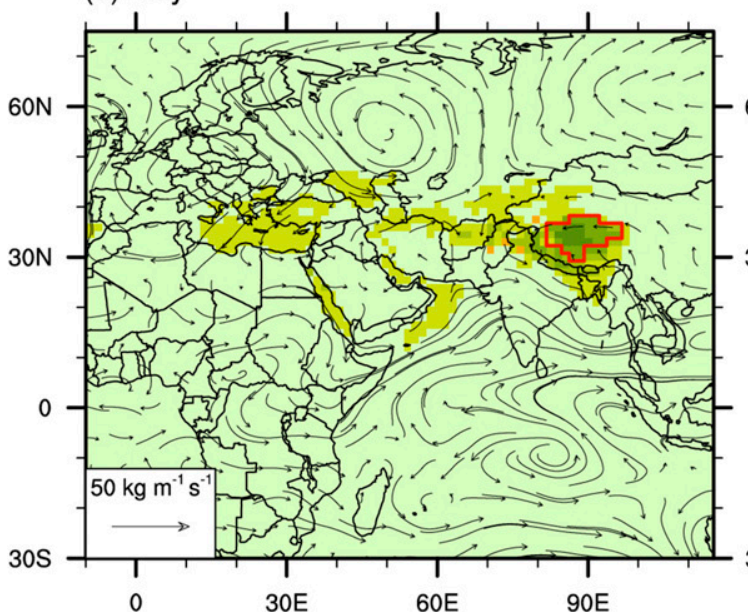

(c) July (b) June

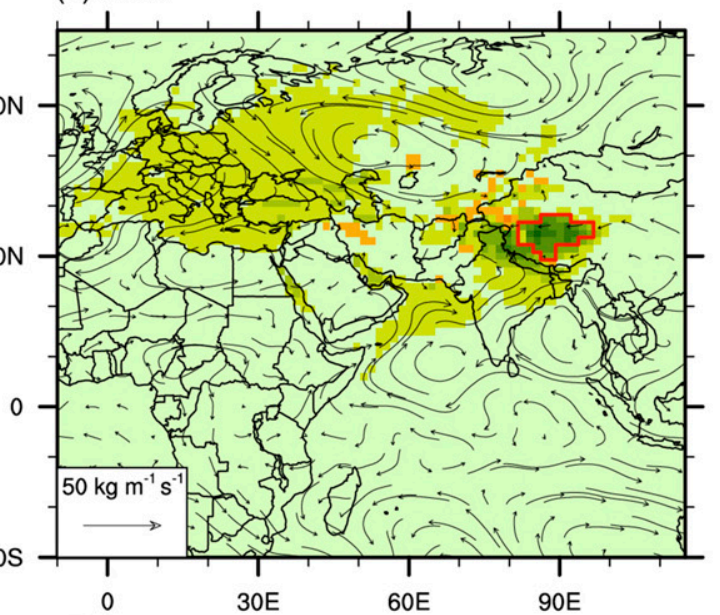

(d) August
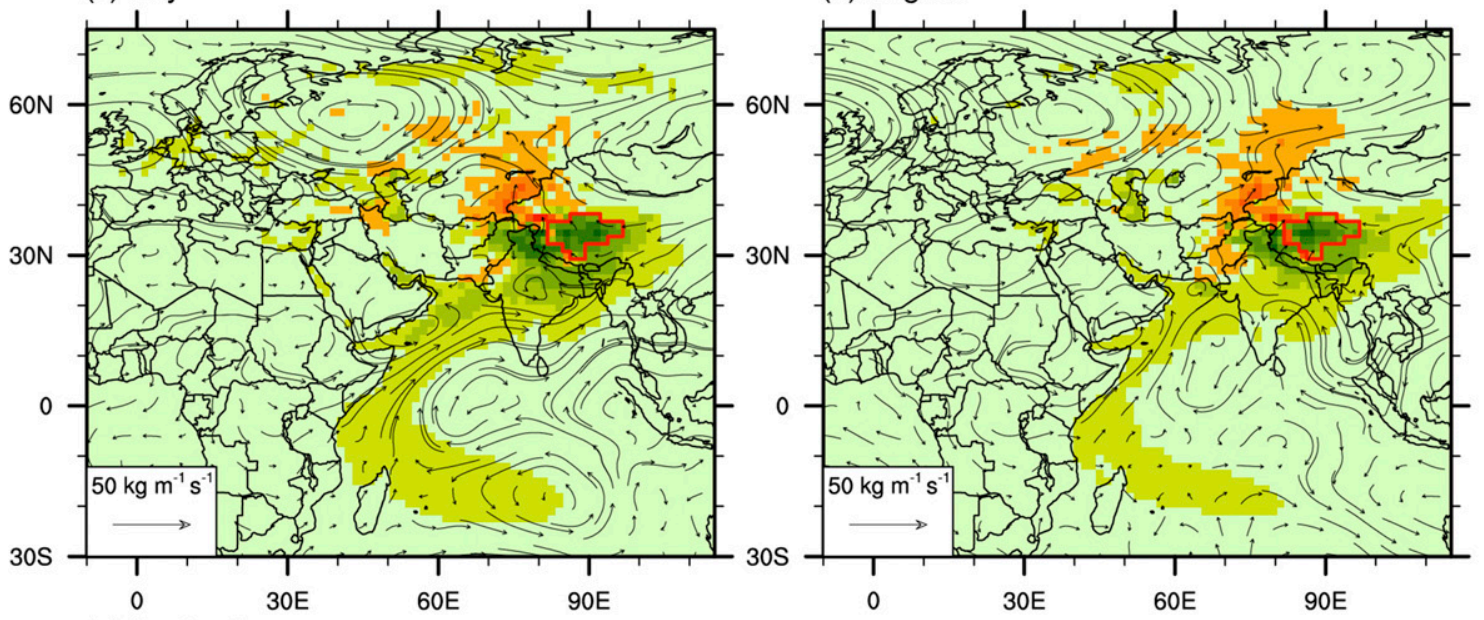

(e) September

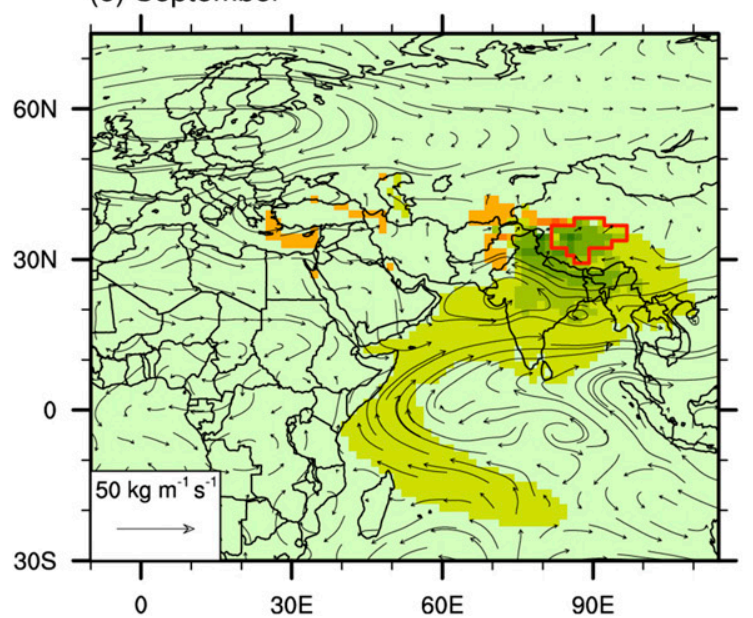

FIG. 6. The monthly from May to September difference of moisture contribution ( $\left.\mathrm{mm} \mathrm{month}^{-1}\right)$ between the wet and dry years using ERA-I (wet mean minus dry mean). The vectors represent the difference of the monthly water vapor flux between the wet and dry years. 
TABLE 1. Subregion contributions to the increased monthly precipitation between the wet and dry years from May to September using ERA-I. The subregions are depicted in Fig. 2a.

\begin{tabular}{lcccc}
\hline \hline & West (\%) & Southwest (\%) & Southeast (\%) & TP (\%) \\
\hline May & 33.4 & 14.5 & 7.4 & 33.0 \\
Jun & 42.0 & 17.8 & 3.8 & 27.4 \\
Jul & 17.3 & 35.3 & 14.5 & 24.8 \\
Aug & 11.5 & 33.5 & 18.3 & 28.9 \\
Sep & 2.3 & 45.5 & 20.1 & 16.4 \\
\hline
\end{tabular}

satellite-derived precipitation estimates. An enhanced version of CMAP (CMAP/A) provides global coverage by filling in gaps with precipitation forecasts from the NCEP-NCAR reanalysis. In this study, the CMAP/A was adopted. The ERA-I precipitation is based on the reanalysis. Although it can contain some bias, it covers the entire region based on model physics and observations for the region. The respective precipitation trends of the three datasets for 1979-2013 are shown in Fig. 7. There are few grids in the targeted area for GPCP and ERA-I that show slightly negative trends, but the overall precipitation trend of the region is apparently positive. The trends for all CMAP/A grids are positive. The calculated change trends of precipitation in the targeted area are $3.6 \%, 6.9 \%$, and $3.0 \%$ decade $^{-1}$ for the GPCP, CMAP/A, and ERA-I datasets, respectively, while it is $8.2 \%$ decade $^{-1}$ for the CMA data. The large spread of trend estimates from different datasets suggests that the trend estimates are subject to large uncertainty because none have included more reliable ground observations. The GPCP and CMAP datasets have combined satellite information to derive precipitation in the remote area without reliable ground observations. These datasets have also suggested a wetting trend over the targeted area, even though the estimated trends are smaller than the estimation based on the CMA data.

A recent study on spatial scales of precipitation variation over the TP shows that the spatial scale in our study area is relatively large (Chen et al. 2016), indicating that the precipitation observation from one station can represent a fairly large area, which adds some confidence to the estimated trends that relied on the small number of CMA stations in this region. Another indirect and independent evidence for the increased precipitation comes from the fact that a majority of the gauge records and station measurements for lake area and water level in the TP shows an increasing trend (Bian et al. 2006; Wu and Zhu 2008; Zhu et al. 2010). Furthermore, a few other studies also reported positive precipitation-minus-evapotranspiration $(P-E)$ changes over the TP (Yang et al. 2011; Yin et al. 2012; Gao et al. (a) GPCP

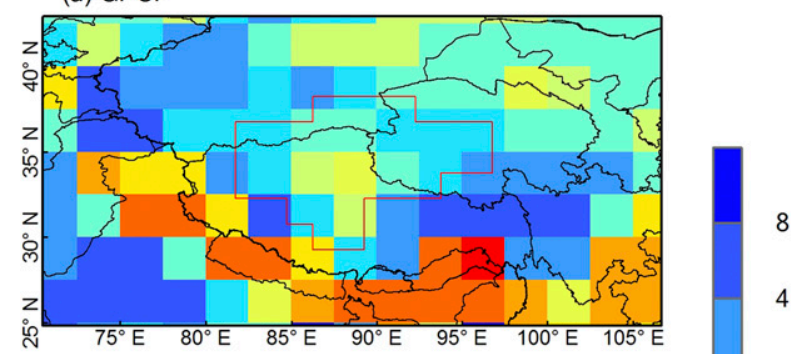

(b) CMAP/A

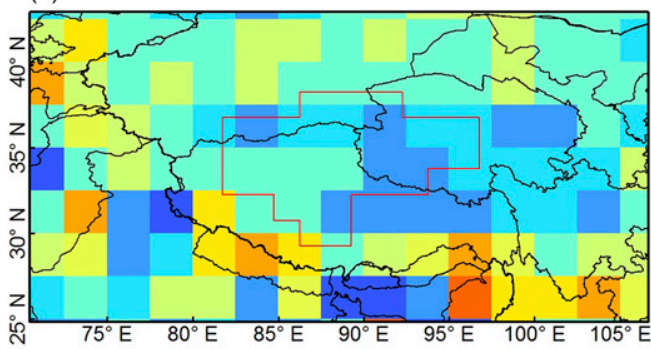

(c) ERA-I

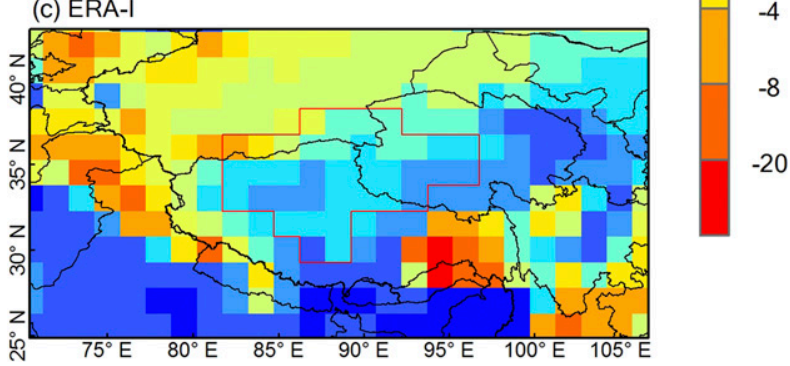

FIG. 7. The annual precipitation trend $\left(\mathrm{mm} \mathrm{yr}^{-1}\right)$ calculated using the (a) GPCP, (b) CMAP/A, and (c) ERA-I datasets over the TP from 1979 to 2013.

2014), indicating that the TP indeed became wetter in general. According to a recent assessment on the environmental changes over the TP (Chen et al. 2015), which were based on all the existing scientific evidence, the overall precipitation of the plateau was increased recently at a rate of $2.2 \%$ decade $^{-1}$, and precipitation of the northern plateau increased markedly.

The local and nearby sources in the west and south were estimated to be the most important moisture contributors to the TP (Fig. 2a), although the oceans evaporate more moisture. Chen et al. (2012) found that the dominant moisture source for the TP precipitation is located in the long and narrow area from the Indian subcontinent to the Southern Hemisphere ( $\mathrm{SH}$ ) with the main area in the Indian Ocean. In fact, they found a net positive evaporation minus precipitation $(E-P)$, which represents a net uptake of water (negative for net release of water) for air parcels en route to the TP. A large proportion of the moisture may be lost en route. As a result, only a limited part can reach the target area. Thus, regions with positive $E-P$ values may not 
contribute much, and regions with negative $E-P$ values may provide a significant amount of moisture to the target area (Drumond et al. 2011). Through an improved quantitative method, Sun and Wang (2014) investigated the moisture origin of the eastern TP. They found that the oceanic sources directly contributed only a small portion (around 5\%) of precipitation moisture in both summer and winter. The Eurasian continent was identified as the main moisture source. A 5\% contribution from the oceans to the eastern TP precipitation is a pretty low value, although they did not count all the oceanic sources. In contrast, our estimation shows that more than $21 \%$ of the moisture for the precipitation over the west-central TP came from the oceans (the Black Sea and Caspian Sea included). Given our study area extended more to the west of the $\mathrm{TP}$, more influence from the India monsoon and the surrounding seas is expected.

There have been few studies that examined the longterm change in moisture sources and their contributions to the TP. Guo and Wang (2014) divided the TP into four subregions and studied the local moisture recycling trend in each subregion. They found that except for the western TP, the PRRs in the three other subregions were increasing. This study found consistent significant increasing PRRs for the west-central TP with different datasets.

The moisture contribution climatology from May to September demonstrates the seasonal evolution of the moisture sources (Fig. 5). In May and June, the westerlies brought about the major moisture contribution. The Somali jet and the Indian summer monsoon started to exert influence in June and made major contributions from July to September. From June to August, the influence from the East Asian summer monsoon represented by the contribution from the southeast gradually increased (Fig. 5). In the pattern showing the difference between the wet and dry years (Fig. 6), the extra moisture in May and June between the wet and dry years mainly came from the west and the targeted region itself (Table 1). In July and August, the main sources were from the southwest and the targeted region. In September, it mainly originated from the southwest and southeast. There was a gradual shift in the center of the extra moisture contribution from west to south. Of all the increased moisture from May to September in the wet years, the southwest contributed the most, followed by the targeted region, which demonstrates the important role of extra moisture supply in these sources.

Gao et al. (2014) identified the poleward shift of the East Asian westerly jet stream and poleward moisture transport, and the intensification of the Indian summer monsoon circulation as the main factors that led to the general wetting trend over the TP. Changes in local circulations were also suggested to be responsible for the spatially varying changes in moisture over the TP (Gao et al. 2014). In this study, we identified the southwest and the local region as the most important source regions to sustain the increased moisture during 1979-2013. It was also established that the PRR increased significantly, which made the local moisture an important factor for the regional precipitation. The anomalous southerly moisture flux over the southwest and the TP from July to September indicates that the increased moisture from the southwest could be due to an enhanced Indian summer monsoon with the enhanced Somali jet over the source region, or/and increased evaporation over the region. An examination of the changes in evaporation (not shown) with the reanalyses indeed confirmed the increase. Previous studies pointed out that the Somali jet had experienced a strong positive trend since 1979 (Zhu 2012; Xiao et al. 2015). Meanwhile, the Indian Ocean has experienced a rapid warming during the last century, especially in the western part (Roxy et al. 2014, 2015), which has provided more evaporated moisture. The enhanced moisture transport from the western Indian Ocean to the TP has most likely contributed to the increased TP precipitation.

\section{Conclusions}

We have examined the precipitation change over the targeted west-central TP over the last few decades. There is a large spread in the estimated trend of precipitation due to sparsely distributed ground observations. Although the magnitudes of the estimated trends using different datasets differ, it seems that all the datasets suggest a wetting trend over the targeted area. Despite the large uncertainty, an overall wetting over the targeted area can be considered most likely. By applying WAM with two atmospheric reanalyses, the moisture origin of the precipitation over the targeted area was identified at both annual and monthly scales and the changes in moisture origin were analyzed. Focusing on the relative changes of the moisture contribution among different source regions, the following conclusions were drawn.

1) The moisture supplied to the annual precipitation over the targeted region came mainly from the land over and around the targeted region, especially from the west and the south. The terrestrial sources provide more than $69 \%$ (64\%) of the moisture for the precipitation, based on ERA-I (NCEP-2). The oceanic 
sources provided more than $21 \%$ of the total moisture supply for the precipitation over the targeted region. The westerlies and the Indian summer monsoon transported the most moisture climatologically. The west-central TP itself contributed about $18 \%$ of the moisture for the precipitation on average. According to the trend analysis, most of the overall increased moisture from 1979 to 2013 was contributed by sources in the southwest and the west-central $\mathrm{TP}$, while the contributions from sources in the west were small.

2) The major moisture source region for the precipitation over the targeted region varied seasonally. The transport by the westerlies dominated the moisture contribution in May and June. From July to August, the westerlies, the Indian summer monsoon (ISM), and the East Asian summer monsoon (EASM) all made significant contributions to the moisture that caused precipitation over the targeted region. The ISM and EASM also dominated the extra moisture contribution in the wet years. In September, the ISM and EASM provided the major moisture contribution to the precipitation over the targeted region both climatologically and in terms of the extra moisture in the wet years.

3) The southwest and the west-central TP provided most of the increased moisture from 1979 to 2013, essentially during the wet season. The enhanced water vapor transport from the western Indian Ocean, via India, to the TP during July and September and the intensification of the local hydrological recycling seem to be the primary processes that provided major moisture for the recent wetting of the TP.

Given the uncertainties in the precipitation over the study region and evaporation estimates over the surrounding regions, the estimated moisture contributions contain a large uncertainty. Future studies are desirable to quantify and to eventually reduce these uncertainties.

Acknowledgments. This work was funded by the National Natural Science Foundation of China (41425002), the National Youth Top-Notch Talent Support Program in China, and the National Basic Research Program of China (2012CB955403). Support from Swedish VR, STINT, BECC, MERGE, and SNIC through S-CMIP are also acknowledged. The authors thank Patrick T. Brown of Duke University, Laifang Li of Woods Hole Oceanographic Institution, and Siao Sun of the Institute of Geographic Sciences and Natural Resources Research, Chinese Academy of Sciences, for the comments and editorial advice; and Yan Shen of the National
Meteorological Information Center, CMA, for providing the stations' location information.

\section{REFERENCES}

Adler, R. F., and Coauthors, 2003: The Version-2 Global Precipitation Climatology Project (GPCP) monthly precipitation analysis (1979-present). J. Hydrometeor., 4, 1147-1167, doi:10.1175/1525-7541(2003)004<1147:TVGPCP > 2.0.CO;2.

Bian, D., Z. Yang, L. Li, D. Chu, G. Zhuo, C. Bianba, Y. Zhaxi, and Y. Dong, 2006: The response of lake area change to climate variations in the North Tibetan Plateau during the last 30 years (in Chinese with English abstract). Acta Geogr. Sin., 61, 510 518, doi:10.11821/xb200605007.

Brubaker, K. L., D. Entehabi, and P. S. Eagleson, 1993: Estimation of continental precipitation recycling. J. Climate, 6, 1077-1089, doi:10.1175/1520-0442(1993)006<1077:EOCPR > 2.0.CO;2.

Chen, B., X. Xu, S. Yang, and W. Zhang, 2012: On the origin and destination of atmospheric moisture and air mass over the Tibetan Plateau. Theor. Appl. Climatol., 110, 423-435, doi:10.1007/ s00704-012-0641-y.

Chen, D., and Coauthors, 2015: Assessment of past, present and future environmental changes on the Tibetan Plateau (in Chinese with English abstract). Chin. Sci. Bull., 32, 3025-3035, doi:10.1360/N972014-01370.

— , Y. Tian, T. Yao, and T. Ou, 2016: Satellite measurements reveal strong anisotropy in spatial coherence of climate variations over the Tibet Plateau. Sci. Rep., 6, 30304, doi:10.1038/ srep30304.

Curio, J., F. Maussion, and D. Scherer, 2015: A 12-year high-resolution climatology of atmospheric water transport over the Tibetan Plateau. Earth Syst. Dyn., 6, 109-124, doi:10.5194/esd-6-109-2015.

Dee, D. P., and Coauthors, 2011: The ERA-Interim reanalysis: Configuration and performance of the data assimilation system. Quart. J. Roy. Meteor. Soc., 137, 553-597, doi:10.1002/qj.828.

Drumond, A., R. Nieto, and L. Gimeno, 2011: Sources of moisture for China and their variations during drier and wetter conditions in 2000-2004: A Lagrangian approach. Climate Res., 50, 215-225, doi:10.3354/cr01043.

Feng, L., and T. Zhou, 2012: Water vapor transport for summer precipitation over the Tibetan Plateau: Multidata set analysis. J. Geophys. Res., 117, D20114, doi:10.1029/ 2011JD017012.

Gao, Y., C. Lan, and Y. Zhang, 2014: Changes in moisture flux over the Tibetan Plateau during 1979-2011 and possible mechanisms. J. Climate, 27, 1876-1893, doi:10.1175/JCLI-D-13-00321.1.

$\longrightarrow$, X. Li, L. R. Leung, D. Chen, and J. Xu, 2015: Aridity changes in the Tibetan Plateau in a warming climate. Environ. Res. Lett., 10, 034013, doi:10.1088/1748-9326/10/3/034013.

Guo, Y., and C. Wang, 2014: Trends in precipitation recycling over the Qinghai-Xizang Plateau in last decades. J. Hydrol., 517, 826-835, doi:10.1016/j.jhydrol.2014.06.006.

Gustafsson, M., D. Rayner, and D. Chen, 2010: Extreme rainfall events in southern Sweden: Where does the moisture come from? Tellus, 62A, 605-616, doi:10.1111/j.1600-0870.2010.00456.x.

Huang, Y., and X. Cui, 2015: Moisture sources of an extreme precipitation event in Sichuan, China, based on the Lagrangian method. Atmos. Sci. Lett., 16, 177-183, doi:10.1002/asl2.562.

Huffman, G. J., R. F. Adler, D. T. Bolvin, and G. Gu, 2009: Improving the global precipitation record: GPCP Version 2.1 . Geophys. Res. Lett., 36, L17808, doi:10.1029/2009GL040000. 
Kanamitsu, M., W. Ebisuzaki, J. Woollen, S.-K. Yang, J. J. Hnilo, M. Fiorino, and G. L. Potter, 2002: NCEP-DOE AMIP-II reanalysis (R-2). Bull. Amer. Meteor. Soc., 83, 1631-1643, doi:10.1175/BAMS-83-11-1631.

Klein, J. A., K. A. Hopping, E. T. Yeh, Y. Nyima, R. B. Boone, and K. A. Galvin, 2014: Unexpected climate impacts on the Tibetan Plateau: Local and scientific knowledge in findings of delayed summer. Global Environ. Change, 28, 141-152, doi:10.1016/j.gloenvcha.2014.03.007.

Krause, P., S. Biskop, J. Helmschrot, W.-A. Flügel, S. Kang, and T. Gao, 2010: Hydrological system analysis and modelling of the Nam Co basin in Tibet. Adv. Geosci., 27, 29-36, doi:10.5194/adgeo-27-29-2010.

Lan, C., Y. Zhang, Q. Wang, L. Zhang, B. Zhou, Z. Hao, and F. Su, 2013: Climate change on the northern Tibetan Plateau during 1957-2009: Spatial patterns and possible mechanisms. J. Climate, 26, 85-109, doi:10.1175/JCLI-D-11-00738.1.

Liu, W., L. Wang, D. Chen, K. Tu, C. Ruan, and Z. Hu, 2016: Large-scale circulation classification and its links to observed precipitation in the eastern and central Tibetan Plateau. Climate Dyn., 46, 3481, doi:10.1007/s00382-015-2782-z.

Liu, Y., B. Hoskins, and M. Blackburn, 2007: Impact of Tibetan orography and heating on the summer flow over Asia. J. Meteor. Soc. Japan, 85B, 1-19, doi:10.2151/jmsj.85B.1.

Moore, G. W. K., 2012: Surface pressure record of Tibetan Plateau warming since the 1870 s. Quart. J. Roy. Meteor. Soc., 138, 1999-2008, doi:10.1002/qj.1948.

Nan, S., P. Zhao, S. Yang, and J. Chen, 2009: Springtime tropospheric temperature over the Tibetan Plateau and evolutions of the tropical Pacific SST. J. Geophys. Res., 114, D10104, doi:10.1029/2008JD011559.

Numaguti, A., 1999: Origin and recycling processes of precipitating water over the Eurasian continent: Experiments using an atmospheric general circulation model. J. Geophys. Res., 104, 1957-1972, doi:10.1029/1998JD200026.

Roxy, M. K., K. Ritika, P. Terray, and S. Masson, 2014: The curious case of Indian Ocean warming. J. Climate, 27, 8501-8509, doi:10.1175/JCLI-D-14-00471.1.

,,,--- R. Murtugudde, K. Ashok, and B. N. Goswami, 2015: Drying of Indian subcontinent by rapid Indian Ocean warming and a weakening land-sea thermal gradient. Nat. Commun., 6, 7423, doi:10.1038/ncomms8423.

Stohl, A., and P. James, 2004: A Lagrangian analysis of the atmospheric branch of the global water cycle. Part I: Method description, validation, and demonstration for the August 2002 flooding in central Europe. J. Hydrometeor., 5, 656-678, doi:10.1175/1525-7541(2004)005<0656:ALAOTA>2.0.CO;2.

Sugimoto, S., K. Ueno, and W. Sha, 2008: Transportation of water vapor into the Tibetan Plateau in the case of a passing synoptic-scale trough. J. Meteor. Soc. Japan, 86, 935-949, doi:10.2151/jmsj.86.935.

Sun, B., and H. Wang, 2014: Moisture sources of semiarid grassland in China using the Lagrangian particle model FLEXPART J. Climate, 27, 2457-2474, doi:10.1175/JCLI-D-13-00517.1.

Sun, Y., and Y. H. Ding, 2011: Responses of South and East Asian summer monsoons to different land-sea temperature increases under a warming scenario. Chin. Sci. Bull., 56, 2718 2726, doi:10.1007/s11434-011-4602-0. van der Ent, R. J., and H. H. G. Savenije, 2011: Length and time scales of atmospheric moisture recycling. Atmos. Chem. Phys., 11, 1853-1863, doi:10.5194/acp-11-1853-2011.

,,-- B. Schaefli, and S. C. Steele-Dunne, 2010: Origin and fate of atmospheric moisture over continents. Water Resour. Res., 46, W09525, doi:10.1029/2010WR009127.

- O. Tuinenburg, H.-R. Knoche, H. Kunstmann, and H. H. G. Savenije, 2013: Should we use a simple or complex model for moisture recycling and atmospheric moisture tracking? Hydrol. Earth Syst. Sci., 17, 4869-4884, doi:10.5194/ hess-17-4869-2013.

$\mathrm{Wu}, \mathrm{Y}$., and L. Zhu, 2008: The response of lake-glacier variations to climate change in Nam Co Catchment, central Tibetan Plateau, during 1970-2000. J. Geogr. Sci., 18, 177-189, doi:10.1007/ s11442-008-0177-3.

Xiao, Z., W. Shi, and P. Yang, 2015: Possible causes of the interdecadal transition of the Somali jet around the late 1990s. J. Meteor. Res., 29, 214-227, doi:10.1007/s13351-015-4103-1.

Xie, P., and P. A. Arkin, 1997: Global precipitation: A 17-year monthly analysis based on gauge observations, satellite estimates, and numerical model outputs. Bull. Amer. Meteor. Soc., 78, 2539-2558, doi:10.1175/1520-0477(1997)078<2539: GPAYMA $>2.0 . \mathrm{CO} ; 2$

Yang, K., B. Ye, D. Zhou, B. Wu, T. Foken, J. Qin, and Z. Zhou, 2011: Response of hydrological cycle to recent climate changes in the Tibetan Plateau. Climatic Change, 109, 517-534, doi:10.1007/s10584-011-0099-4.

Yao, T. L., and Coauthors, 2012: Different glacier status with atmospheric circulations in Tibetan Plateau and surroundings. Nat. Climate Change, 2, 663-667, doi:10.1038/ nclimate1580.

Yin, Y., S. Wu, D. Zhao, D. Zheng, and T. Pan, 2012: Impact of climate change on actual evapotranspiration on the Tibetan Plateau during 1981-2010 (in Chinese with English abstract). Acta Geogr. Sin., 67, 1471-1481, doi:10.11821/xb201211004.

You, Q., S. Kang, E. Aguilar, and Y. Yan, 2008: Changes in daily climate extremes in the eastern and central Tibetan Plateau during 1961-2005. J. Geophys. Res., 113, D07101, doi:10.1029/ 2007JD009389.

Zhao, Y., and J. Zhu, 2015: Assessing quality of grid daily precipitation datasets in China in recent 50 years (in Chinese with English abstract). Plateau Meteor., 24, 837-845, doi:10.7522/ j.issn.1000-0534.2013.00141.

, - - and Y. Xu, 2014: Establishment and assessment of the grid precipitation datasets in China for recent 50 years (in Chinese with English abstract). J. Meteor. Sci., 34, 414-420, doi:10.3969/2013jms.0008.

Zhou, X., Y. Zhang, Y. Yang, Y. Yang, and S. Han, 2013: Evaluation of anomalies in GLDAS-1996 dataset. Water Sci. Technol., 67, 1718-1727, doi:10.2166/wst.2013.043.

Zhu, L., M. Xie, and Y. Wu, 2010: Quantitative analysis of lake area variations and the influence factors from 1971 to 2004 in the Nam Co basin of the Tibet Plateau. Chin. Sci. Bull., 55, 1294, doi:10.1007/s11434-010-0015-8.

Zhu, Y., 2012: Variations of the summer Somali and Australia cross-equatorial flows and the implications for the Asian summer monsoon. Adv. Atmos. Sci., 29, 509-518, doi:10.1007/ s00376-011-1120-6. 